Tailoring the morphology of poly(ethylene oxide)/silver triflate blends: from crystalline to selfassembled nanofibrillar structures

This article has been downloaded from IOPscience. Please scroll down to see the full text article.

2013 Nanotechnology 24055602

(http://iopscience.iop.org/0957-4484/24/5/055602)

View the table of contents for this issue, or go to the journal homepage for more

Download details:

IP Address: 129.81.226.149

The article was downloaded on 02/08/2013 at 10:18

Please note that terms and conditions apply. 


\title{
Tailoring the morphology of poly(ethylene oxide)/silver triflate blends: from crystalline to self-assembled nanofibrillar structures
}

\author{
Vincenzo Caramia ${ }^{1}$, Ilker S Bayer ${ }^{1}$, George C Anyfantis ${ }^{1}$, \\ Roberta Ruffilli ${ }^{2}$, Farouk Ayadi ${ }^{1}$, Luigi Martiradonna ${ }^{3}$, \\ Roberto Cingolani $^{2}$ and Athanassia Athanassiou ${ }^{1}$ \\ ${ }^{1}$ Nanophysics, Istituto Italiano di Tecnologia, via Morego 30, I-16163 Genova, Italy
2 Istituto Italiano di Tecnologia, via Morego 30, I-16163 Genova, Italy
${ }^{3}$ Center for Biomolecular Nanotechnologies, Istituto Italiano di Tecnologia@ UniLe, via Barsanti 1,
73010, Arnesano, Lecce, Italy \\ E-mail: ilker.bayer@iit.it and athanassia.athanassiou@iit.it
}

Received 11 August 2012, in final form 5 December 2012

Published 11 January 2013

Online at stacks.iop.org/Nano/24/055602

\begin{abstract}
Interaction of polyethylene oxide (PEO) with transition metal triflates is a newly emerging research area due to its numerous application fields, such as thin-film power conversion devices and sensors. In the present study, we demonstrate, for the first time, that PEO can solvate silver triflate organic salts in large quantities when formic acid is used as a common solvent for both. Nanocomposites with unique structural and electrical properties are fabricated by simply drop casting formic acid solutions of PEO and silver triflate salts. We present a detailed experimental study on the characterization of morphological and electrical properties of PEO-silver triflate nanocomposite films as a function of silver triflate concentration and discuss their potential applications as humidity sensors. In particular, by increasing the concentration of the salt in the initial solution the morphological features of the formed nanocomposites can be varied from well defined microcrystals to amorphous nanofibers. Of special interest are the nanocomposite films fabricated from a 1:1 (PEO-unit: $\mathrm{Ag}^{+}$) molar ratio, since they consist of self-assembled nanofibrillar structures, which exhibit good electrical conductivity as well as highly repeatable sensitivity towards humidity.
\end{abstract}

S Online supplementary data available from stacks.iop.org/Nano/24/055602/mmedia

(Some figures may appear in colour only in the online journal)

\section{Introduction}

Polyethylene oxide (PEO) is a flexible, nontoxic, water soluble polyether, which has been used in various applications such as pharmaceutical formulations, food additives and cosmetics. Most of all, it has been studied extensively as a coordination polymer in the fabrication of polymer electrolytes because it can act as a solid solvent for salts with an emphasis on lithium salts, facilitating ion mobility in the solid state [1]. PEO as solid polymer electrolyte has many advantages over its liquid organic solution counterparts due to its ease of processing, stable electrochemical characteristics and excellent mechanical properties [2]. Indeed, it is well known that PEO is an ideal host matrix for lithium salts [3] traditionally employed in Li-ion batteries (LIBs) in order to create nanocomposite polymer electrolytes in 
combination with ceramic nanofillers such as titania or alumina nanoparticles [1]. However, the highly crystalline characteristics of PEO cause a retardation of lithium ion transport, resulting in a poor ionic conductivity below its melting point. To circumvent this drawback, organic plasticizers or polar solvents have been incorporated into the PEO matrix to form gel electrolytes [4-7]. In addition, PEO serves as a host polymer for other metallic salts such as $\mathrm{AgNO}_{3}$ or $\mathrm{AgBF}_{4}$ in order to create nanocomposites for different purposes, such as for instance, propane and propylene sorption $[8,9]$, olefin from paraffin separation [10], conducting polymer electrolytes $[11,12]$ and electronic devices and energy power systems with tunable electrical properties in combination with electrically conducting polymers such as polyaniline [13].

In situ generation of metallic nanoparticles in polymer matrices can be achieved by a number of chemical or physical pathways, such as light induced reduction and growth [14], catalytic effects of polymer crosslinkers [15] or laser ablation induced generation and dispersion in polymer solutions [16]. For the PEO polymer matrix, in particular, a number of studies have demonstrated incorporation of silver nanoparticles into the PEO matrix using magnetron sputtering in order to achieve inhibition of bacterial growth and for antifouling purposes [17-21]. In addition, electrospinning techniques were also used to incorporate silver nanoparticles into the PEO host matrix to fabricate antimicrobial nanofibers [22]. Finally, electrospun PEO fibers in combination with conducting polymers, carbon nanotubes or chitosan have been commonly used to fabricate functional PEO nanofibers [23-25].

Recently a number of studies [26-28] have presented composite systems of PEO and silver trifluoromethanesulfonate salt, a.k.a. silver triflate $\left(\mathrm{CAgF}_{3} \mathrm{O}_{3} \mathrm{~S}\right)$, to maintain a certain degree of silver ion-conductivity for applications as nanocomposite polymer electrolytes. No detailed analysis or characterization of the effect of silver triflate concentration on the final composite properties and morphology including the effect of solvents has been presented so far. Therefore, in the present study, we report on the formation and characterization of new nanostructured composites from PEO-silver triflate dissolved in formic acid prepared by simple solution casting onto glass or silicon wafers. We demonstrate the existence of a gradual transition from crystalline films to amorphous nanofibers of PEO, by a simple self-assembly mechanism, as the quantity of silver salt gradually increases without the use of the electrospinning technique. The self-assembled nanofibrillar bundle structure was also found to incorporate a network of channels of silver compounds, which render the nanofibrous network electrically conductive. The amorphous character of the formed PEO nanofibers makes the specific system promising for thin-film solid-state Li-ion battery applications as well. Moreover, the large surface area due to the nanofibrillar morphology opens up new possibilities for their potential use as solid-state humidity sensors. Indeed, electrical measurements in controlled humidity environments resulted in highly reproducible conductivity changes as a function of the environmental relative humidity $(\mathrm{RH})$.

\section{Experimental section}

In a typical procedure, a solution of PEO (MW: 100000) in formic acid (100 mg ml${ }^{-1}$ ) was blended with different solutions of silver triflate $\left(\mathrm{AgCF}_{3} \mathrm{SO}_{3}\right)$ in formic acid (see supporting information table 1 , available at stacks.iop.org/ Nano/24/055602/mmedia, for details) and then the resulting solution was drop-cast after ca. 5-10 min onto a glass and silicon substrate. Note that ultrasonication or magnetic stirring for the preparation of PEO solution was avoided since this type of mixing causes degradation of the polymer by inducing polymeric chain cleavage. The film on the glass slide substrate, covered with a Petri dish in order to slow down the evaporation rate of the solvent, was left to dry in ambient conditions for three days in the presence of ordinary white room light.

The optical microscope measurements were made by a Zeiss Scope A.1 microscope with polarized light. The surface morphology of the nanocomposite films was analyzed by an atomic force microscope (AFM), Park Systems XE-100, in non-contact mode, using a silicon cantilever. An adaptive scan rate set between 0.15 and $0.25 \mathrm{~Hz}$ was utilized for all the samples. The surface morphology and composition of the composite films were characterized using a JEOL JSM-6490LA variable pressure scanning electron microscope (SEM), operated in high-vacuum mode at $15 \mathrm{kV}$, equipped with an energy dispersive $\mathrm{x}$-ray spectroscopy (EDS) analyzer. Higher details of the PEO fibers were collected on a JEOL JSM-7500FA field emission scanning electron microscope, working at $15 \mathrm{kV}$. The cross sectional analysis of the films was performed on a JEOL JEM-1011 transmission electron microscope (TEM), working at $100 \mathrm{kV}$, equipped with a digital camera Gatan Orius 1000. Thin sections (about $50 \mathrm{~nm}$ thick) for the cross sectional analyses were dry cut at room temperature with a Leica Microsystem EM UC6 ultramicrotome, using the dedicated antistatic device. Differential scanning calorimetry experiments (DSC) were performed with a TA Instruments Q2000 differential scanning calorimeter for the observation of PEO melting. Measurements were performed from 20 to $100^{\circ} \mathrm{C}$ and subjected to an underlying heating rate of $5^{\circ} \mathrm{C} \mathrm{min}{ }^{-1}$ under constant nitrogen flow. Universal Analysis software is used to calculate the heat of fusion $\left(\Delta H_{\mathrm{f}}\right)$ in order to estimate percentage crystallinity based upon $203 \mathrm{~J} \mathrm{~g}^{-1}$ for the $100 \%$ crystalline PEO. The degree of crystallinity ( $\left.\% X_{\mathrm{c}}\right)$ was calculated according to equation (1):

$$
\% X_{\mathrm{c}}=\left(\Delta H_{\mathrm{f}} / \Delta H_{\mathrm{f} 0}\right) \times 100
$$

where $\Delta H_{\mathrm{f}}$ is the heat of fusion of the sample and $\Delta H_{\mathrm{f} 0}$ is the heat of fusion of $100 \%$ crystalline PEO. X-ray diffraction (XRD) measurements were conducted using a Panalytical X'Pert PRO, using a $\mathrm{Cu} \mathrm{K} \alpha$ diffractometer at $45 \mathrm{kV}$ and $40 \mathrm{~mA}$ with an analysis mode of grazing incidence.

Electrical characteristics of the nanocomposites were measured using an Agilent 4155B Semiconductor Analyzer interfaced with a Karl Suss RA150 Probe Station. Samples were biased from 0 to $+5 \mathrm{~V}$ and from 0 to $-5 \mathrm{~V}$. Moreover, current-voltage $(I-V)$ data were recorded at $0.1 \mathrm{~V}$ intervals. 


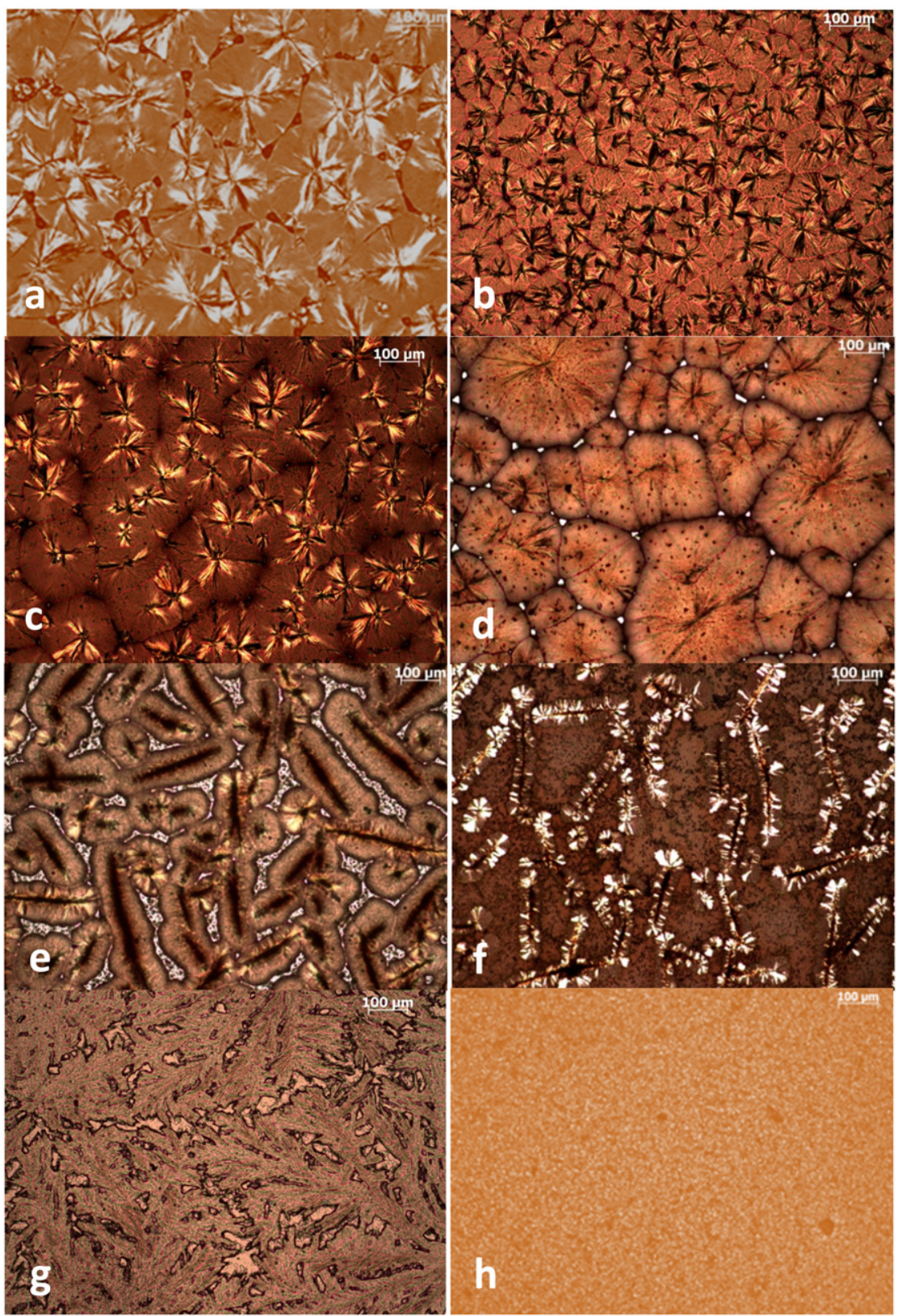

Figure 1. Optical images of (a) pure $\mathrm{PEO}$ and $\mathrm{PEO} / \mathrm{AgCF}_{3} \mathrm{SO}_{3}$ nanocomposites using different concentrations of $\mathrm{AgCF}_{3} \mathrm{SO}_{3}$ : (b) 0.1 wt $\%$, (c) $1.0 \mathrm{wt} \%$, (d) $9.1 \mathrm{wt} \%$, (e) $16.6 \mathrm{wt} \%$, (f) $28.6 \mathrm{wt} \%$, (g) $60.0 \mathrm{wt} \%$ and (h) $84.8 \mathrm{wt} \%$.

Conductive silver paste electrodes were painted on the sample surfaces in order to minimize the contact resistance. A minimum of five $I-V$ measurements were taken from each sample at different time intervals in order to assess the electrical stability and repeatability of the measurements.

Electrochemical impedance spectroscopy (EIS) measurements were performed with a computer-controlled AUTOLAB PGSTAT $302 \mathrm{~N}$ potentiostat operating in a two-electrode mode. All the measurements were carried out at zero bias potential in the $300 \mathrm{kHz}-0.01 \mathrm{~Hz}$ frequency range and applying an $\mathrm{AC}$ voltage of $5 \mathrm{mV}$. The electrochemical cell consists of two identical platinized glass substrates sealed with a Parafilm gasket which acted as soft spacer. The squared polymer electrolyte film was sandwiched between the two platinum electrodes, which were prepared by electron beam evaporation. All the films had the same thickness $(100 \mu \mathrm{m})$ and the same active area $\left(\mathrm{ca} .1 \mathrm{~cm}^{2}\right)$.

\section{Results and discussions}

A series of thin nanocomposite films was prepared by drop casting formic acid solutions of PEO and silver triflate salt with increasing salt concentrations and the resultant morphology was investigated using optical, scanning electron and atomic force microscope measurements. The optical image in figure 1(a) presents a typical example of crystalline PEO, whose crystallization behavior is already well documented [3, 29], obtained by drop casting from a formic acid solution. In the formed films, crystalline spherulites of similar size impinging upon each other are 


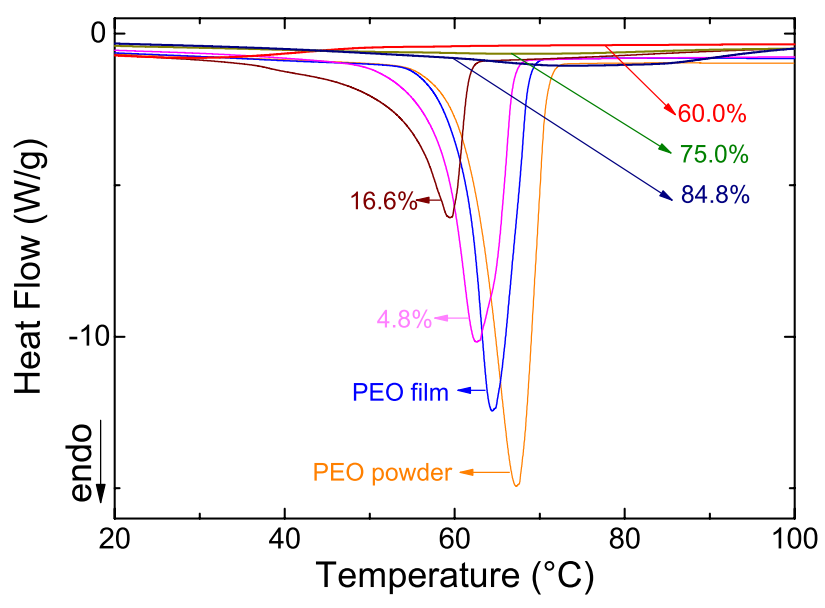

Figure 2. Differential scanning calorimetry (DSC) data of pure PEO and selected PEO-silver triflate composite films. The demonstrated curves are endothermic, characteristic for the melting of the polymer.

clearly seen. The morphology of the crystalline structures in the formed films does not seem to be affected by the addition of small amounts of silver triflate in the initial solution, such as 0.1 and $1.0 \mathrm{wt} \%$ as seen in figures $1(\mathrm{~b})$ and (c), respectively. On the other hand, the composite films obtained from solutions with $9.1 \mathrm{wt} \%$ of silver triflate (figure 1(d)) also exhibit crystalline structures, but the spherulites start losing their similarly symmetric shapes as they vary in size, and jagged edges are more pronounced at this salt concentration. As the concentration of silver triflate increases even more in the initial solutions to 16.6 and $28.6 \mathrm{wt} \%$, the optical microscopy images of the respected films (figures 1(e) and (f)) show distinct differences in the shape and distribution of the formed structures compared to the previous morphologies.

In particular, it can be observed that the PEO spherule grains start changing their morphology between 9.1 and $16.6 \mathrm{wt} \%$ silver salt loading. The films obtained from solutions with $16.6 \mathrm{wt} \%$ silver salt loading (figure 1(e)) appear to consist of elongated but still crystalline-like domains, probably incorporating some dissolved silver salt. We propose that the previous polymer spherulites adopt elongated shapes in order to facilitate the self-assembly of the silver compounds. When the silver salt concentration in the solution is $28.6 \mathrm{wt} \%$, the elongated crystalline domains become even thinner (they appear black with thin white shiny regions around them in figure 1(f)), whereas an amorphous-like phase, which should be a mixture of amorphous PEO with different silver compounds, appears to be dominant. Prompted by the effect of the silver salt concentration on the surface morphology of the thin nanocomposite films, we continued to dope PEO with the silver salt loadings up to $84.8 \mathrm{wt} \%$, which corresponds to a molar ratio of $1: 1$ (between the repeating unit of PEO and $\left.\mathrm{Ag}^{+}\right)$. Figures 1(g) and (h) show optical images of thin composite films obtained from solutions with $60.0 \mathrm{wt} \%$ and $84.8 \mathrm{wt} \%$ silver salt loading, respectively. In figure $1(\mathrm{~g})$, earlier macroscopic crystallinity features are hardly observable. Instead, randomly shaped features dispersed inside an overall amorphous background

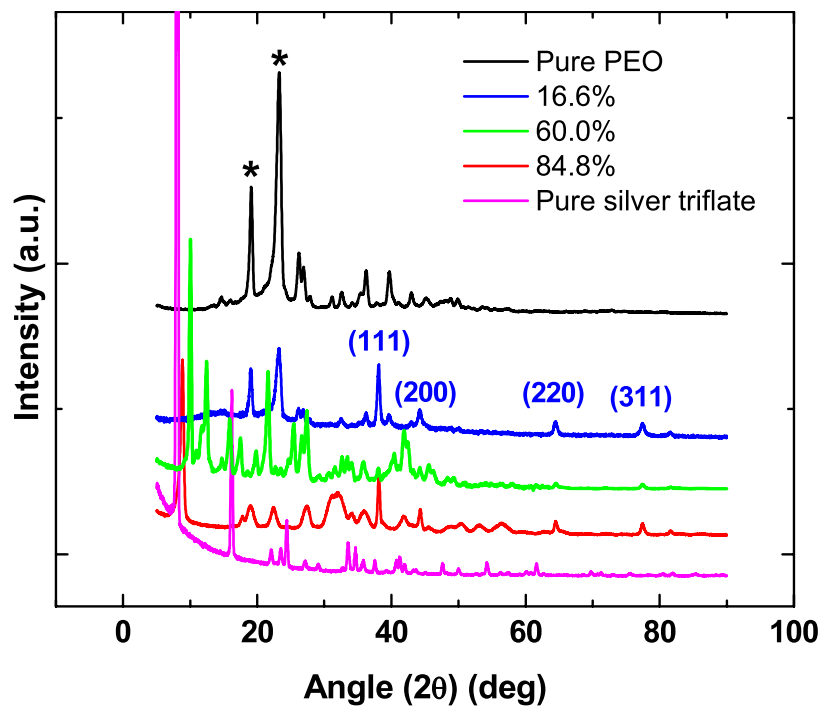

Figure 3. XRD spectra: comparison between pure $\mathrm{PEO}$ and $\mathrm{PEO} / \mathrm{AgCF}_{3} \mathrm{SO}_{3}$ nanocomposites with $84.8 \%, 60.0 \%$ and $16.6 \%$ of silver and pure silver triflate. The two peaks indicated by the asterisk symbol in the XRD plot of pure PEO correspond to crystalline diffraction signals at $2 \theta=19^{\circ}$ and $23^{\circ}$. Metallic silver (peaks that are assigned to the diffraction of (111) at $2 \theta=38^{\circ}$, (200) at $44.2^{\circ},(220)$ at $64.4^{\circ},(311)$ at $77.5^{\circ}$ planes) is present in all the composite samples.

are observed. Disappearance of rod-like features is also noticed. Whereas in figure 1(h), at the highest silver salt loading concentration, a completely amorphous composite film morphology appears under the optical microscope.

In order to support these observations, differential scanning calorimetry (DSC) measurements were conducted on the nanocomposite films, as shown in figure 2. An increase in the silver triflate salt concentration reduces both the melting point of the composites, indicated by the minimum in the melting peak, and the enthalpy of the phase transition, calculated by integrating each curve below the baseline. At and above $60 \%$ silver triflate loading, melting peaks no longer appear, demonstrating the loss of polymer matrix crystallinity [30]. Table 2 in the supporting information (available at stacks.iop.org/Nano/24/055602/mmedia) lists the degree of crystallization obtained from DSC analysis of pure PEO and PEO-silver triflate salts with $4.8 \%$ and $16.6 \%$. As seen in the table, the crystallinity of pure PEO film declines to almost half of its initial value at $16.6 \%$ silver triflate loading.

To have a better insight into the interaction between the polymer and silver salt with increasing silver salt concentration, which resulted in remarkable morphological transformations as shown in the optical microscope images of figure 1, X-ray diffraction (XRD) measurements were conducted on all the composite films (see figure $\mathrm{S} 1$ in the supporting information, available at stacks.iop.org/Nano/ 24/055602/mmedia). In figure 3, samples of XRD spectra of pure PEO and pure silver triflate salt along with three different representative polymer-salt composites are shown. The spectrum of as-received silver salt powder matches with the data presented in earlier reports [31]. The two main 

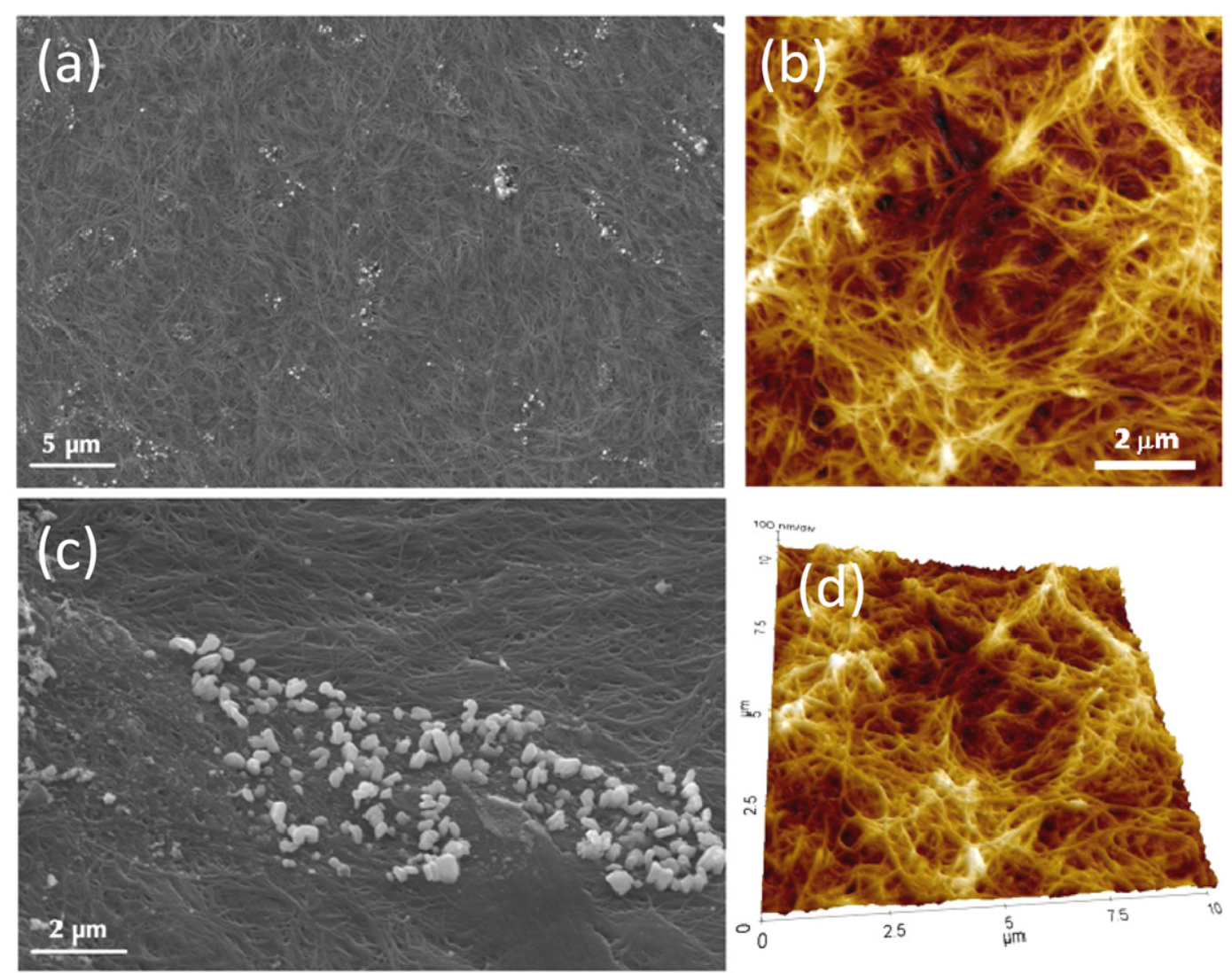

Figure 4. SEM and AFM topographical images of the nanocomposite film obtained by drop casting a formic acid solution of $\mathrm{PEO} / \mathrm{AgCF}_{3} \mathrm{SO}_{3}$ with $84.8 \%$ of silver. The topographies in (a) and (b) show respectively SEM and AFM top views of the coating with PEO nanofibers including regions of silver compound clusters (white regions in the SEM image). Corresponding tilted SEM and 3D AFM images are shown in figures (c) and (d) respectively; in (c), details of these clusters are visible along with nanorods having an average diameter of ca. $200 \mathrm{~nm}$ and perpendicular to the coating surface.

crystalline peaks associated with pure PEO appear at $2 \theta=$ $19^{\circ}$ and $23^{\circ}$, as labeled in figure 3 by the two asterisk symbols. These two peaks also appear in the composites obtained from solutions containing $16.6 \mathrm{wt} \%$ silver salt with a slight shift in the diffraction angles $\left(1.8^{\circ}\right)$, possibly connected to the strained polymer crystals leading to the change of their shape observed in figure 1(e). It is worth noticing that PEO polymer diffraction peaks are hardly noticeable in the composite obtained from the solution with $60.0 \%$ silver salt loading. The same behavior is noticed for all composites obtained from solutions with silver loading between about $50 \%$ and $70 \%$ (figure S1, available at stacks.iop.org/Nano/24/055602/ mmedia). Above this concentration the PEO peaks reappear, as can be seen in figure 3 for the $84.8 \%$ silver salt loaded composite, although their intensities are highly reduced and broadened at both angles, due to the formation of mainly amorphous phases when the Ag ions and PEO repeating units are combined under a 1:1 molar ratio. The PEO seems to be organized differently in the produced composites, depending on the silver salt loading and, therefore, on its interactions with the salt as well as with the reduced metal ion complexes. Formation of metallic silver in all composites is evidenced by the existence of four peaks characteristic of silver $((111)$ at $2 \theta=38^{\circ},(200)$ at $44.2^{\circ},(220)$ at $64.4^{\circ},(311)$ at $77.5^{\circ}$ planes $)$ as identified in figure 3 . The formation of the metallic silver takes place throughout the preparation and drying of the films and it can be attributed to a number of processes, which can take place simultaneously or subsequently, as: (a) the reducing ability of formic acid [32, 33], as demonstrated in figure S2 of the supporting information (available at stacks.iop.org/Nano/ $24 / 055602 /$ mmedia), where reduction of silver salt metallic silver is monitored by UV/spectroscopy in formic acid; (b) the silver ion reduction promoted by the hydroxyl end-groups of PEO polymeric chains; (c) possible photo-reduction in acid dissolved PEO solutions, since the experiments take place under ambient light conditions [34, 35].

For the films formed from the solutions with the highest salt loadings, namely 60.0 and $84.8 \mathrm{wt} \%$, many additional diffraction peaks are visible, most likely due to strong interactions between PEO, the silver salt as well as the reduced metal ion complexes. A number of XRD peaks which could be attributed to the in situ formation of other silver compounds such as $\mathrm{Ag}_{2} \mathrm{~F}$ at $2 \theta=15^{\circ}$ and $\mathrm{Ag}_{8} \mathrm{O}_{4} \mathrm{~S}_{4}$ at $12^{\circ}$ are identified within the composite obtained from the solution with $60.0 \%$ silver salt [36]. Furthermore, various peaks originating from silver oxides, $\operatorname{Ag}_{x} \mathrm{O}$ are seen: such as the (111) peak of $\mathrm{Ag}_{2} \mathrm{O}$ at $2 \theta=32^{\circ}$, appearing in the composite films obtained from solutions $16.6,60.0$ and $84.8 \%$ wt silver salt, and the (002) peak of $\mathrm{AgO}$ at $2 \theta=34^{\circ}$ and (111) peak of $\mathrm{Ag}_{2} \mathrm{O}$ at $2 \theta=37^{\circ}$, appearing in composites obtained 
from solutions with 60.0 and $84.8 \mathrm{wt} \%$ silver salt [37]. The $\mathrm{Ag}_{2} \mathrm{O}$ diffraction peak (220) at $54^{\circ}$ was also detected in the composite obtained from the solution with $84.8 \%$ silver salt loading [38].

Further structural investigations were carried out using atomic force microscope (AFM) and scanning electron microscope (SEM) measurements, in order to better understand the topography of the films, with a particular focus on the films formed from solutions containing $84.8 \mathrm{wt} \%$ of silver triflate, which appear amorphous under the optical microscope. Remarkably, both SEM and AFM measurements revealed that the surface structure of these films consists of nanofibrous bundles, as seen in figure 4. Figures 4(a) (SEM) and 4(b) (AFM) show the 2D surface morphology of the films. Figure 4(c), on the other hand, shows a SEM image of the surface of the same kind of film obtained by tilting the film-coated substrate in the SEM chamber.

Figure 4(d) shows the 3D morphology of the film presented in figure $4(\mathrm{~b})$. The formed polymeric nanofibers cover homogeneously all the underlying substrate, they have an average diameter of ca. $100 \mathrm{~nm}$ and appear entangled and uniformly distributed on the surface of the coating. It is worth noticing that these fibrous structures have been obtained by simple drop casting from formic acid solutions without the use of dedicated techniques for nanofiber fabrication, such as electrospinning [35, 39-41]. Analysis by SEM (figures 4(a) and (c)) shows the presence of discrete regions (in white) where silver compound particles are concentrated. A closer look in figure 4(c) reveals the presence of various randomly shaped but also rod-like nanostructures (with an average diameter of ca. $200 \mathrm{~nm}$ ), which protrude out of the horizontal plane consisting of the self-assembled PEO nanofibers. These nanostructures are believed to be composite structures made up of metallic silver, its oxides or complexes of undissolved silver salt compounds detected in the XRD investigation.

In order to investigate also the bulk morphology of the films, whose surfaces consist of self-assembled nanofibers, we performed TEM image analysis on ca. $50 \mathrm{~nm}$ thick cross section slices of the composites. The TEM investigation demonstrates an extended network of channels and islands made of silver compounds (represented by black color regions in the image in contrast with the white-gray regions attributed to the PEO polymer) randomly distributed within the polymeric matrix (figure 5(a)). These networks of composite silver compound channels most likely emerge as silver nanorods and clusters that protrude out of the PEO fibrous surface, as the SEM images (figure 4) previously revealed. Moreover, a higher resolution cross sectional TEM image from an area free from bulky silver compounds, shown in figure 5(b), reveals the presence of even smaller silver related nanoparticles, with an average size of $5 \mathrm{~nm}$. These nanoparticles are randomly distributed in the bulk of the composite PEO film, and some of these appear to form larger aggregates.

Additional AFM investigations show that the morphology of the composite films made of PEO nanofibers is maintained after subjecting them to thermal treatment up to $150^{\circ} \mathrm{C}$ (see figures S12, S13 in supporting information, available at
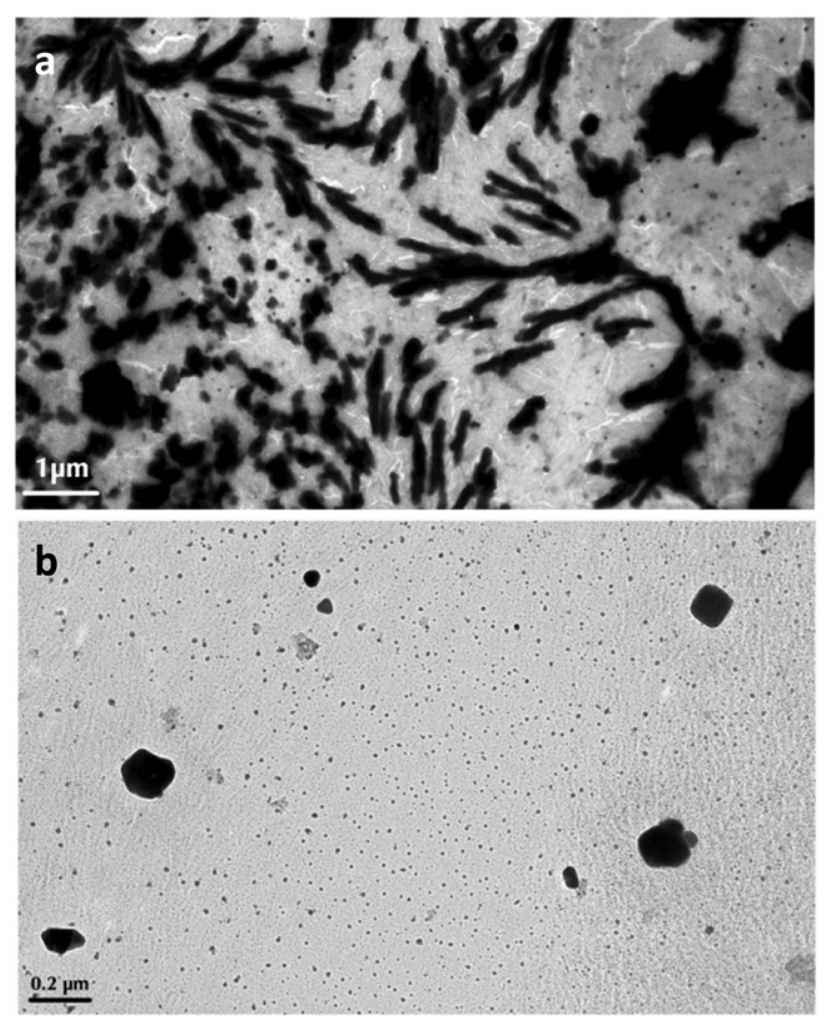

Figure 5. Cross section TEM images in different regions of the thin film containing the PEO nanofibers. (a) shows an extended network of silver compound-containing channels and islands (black color) randomly distributed in different directions through the polymeric matrix. (b) shows the presence of separated silver related nanoparticles with an average size of $5 \mathrm{~nm}$.

stacks.iop.org/Nano/24/055602/mmedia), demonstrating that the presented system is well adapted for high-temperature applications. Thermogravimetric analysis (TGA) shows a slight loss of weight at approximately $130^{\circ} \mathrm{C}$, possibly due to the evaporation of residual volatiles and a sharp loss of weight at $210^{\circ} \mathrm{C}$ corresponding to the decomposition of amorphous PEO polymer in the nanocomposite formed from the solution with $84.8 \mathrm{wt} \%$ of silver salt (see figure S14 in supporting information, available at stacks.iop.org/ Nano/24/055602/mmedia). The decomposition temperature of PEO nanofibers is lower than that of pure PEO powder. Indeed, pure crystalline PEO thermally degrades around $350{ }^{\circ} \mathrm{C}$ [42]. The observed lower thermal degradation of the PEO nanofibers (at a temperature of $210^{\circ} \mathrm{C}$ ) is most likely due to their lower degree of crystallinity compared to PEO films obtained from the PEO powder. This assumption is in agreement with our XRD and DSC findings.

The conductivity mechanism in the produced composites is expected to be more complicated than in the simple polymer-metal nanocomposites, in which conductivity is solely due to electron transfer between embedded metallic nanostructures forming continuous networks. In the present case, existence of semiconductive silver oxides, other silver compounds, as well as dissolved unreacted silver salts in the PEO matrix can induce a combined multi-mode conduction mechanism in the form of electron hopping and tunneling 

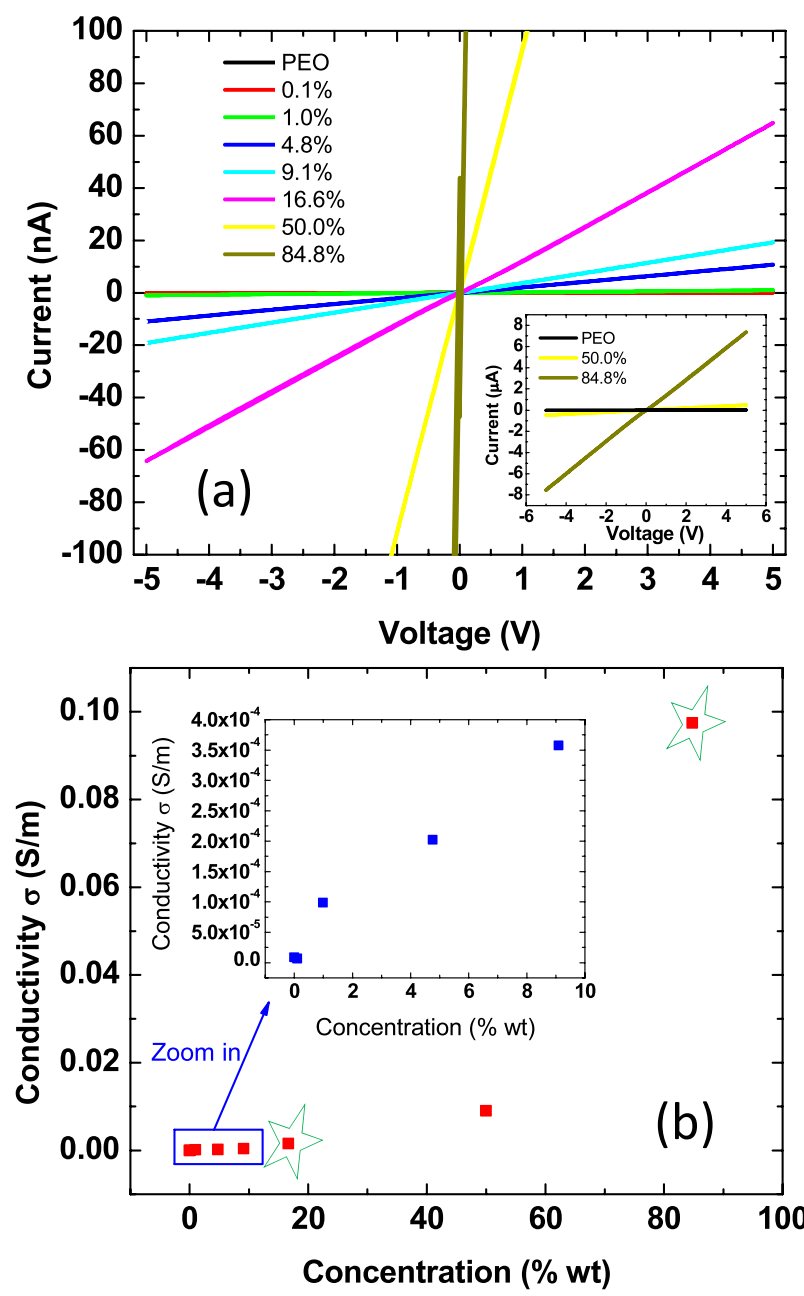

Figure 6. (a) Current-voltage $(I-V)$ characteristic curves for pure $\mathrm{PEO}$ and $\mathrm{PEO} / \mathrm{AgCF}_{3} \mathrm{SO}_{3}$ nanocomposite films for different wt $\%$ concentrations $(0.1,1.0,4.8,9.1,16.6,50.0$ and 84.8) of $\mathrm{AgCF}_{3} \mathrm{SO}_{3}$. Inset: $I-V$ characteristic curves for pure PEO, $50.0 \%$ and $84.8 \%$ nanocomposites. (b) DC electrical conductivity $\sigma$ $\left(\mathrm{S} \mathrm{m}^{-1}\right.$ ) versus concentration (wt\%) of silver triflate in the nanocomposite $\mathrm{PEO} / \mathrm{AgCF}_{3} \mathrm{SO}_{3}$ films and in the pure $\mathrm{PEO}$ polymer. The inset represents electrical conductivity versus concentration of silver salt ranging from $0.0 \mathrm{wt} \%$ (pure PEO polymer) up to $9.1 \mathrm{wt} \%$ in the nanocomposite.

through silver compound nanostructures and charge carrier transport within the composite. For this reason the films were characterized by impedance spectroscopy. The data and the measurement details are presented in the supporting information (figure S16, available at stacks.iop.org/Nano/24/ 055602/mmedia). Complex impedance plots of pure PEO films and composite films generated from solutions with $16.6 \%$ and $84.8 \%$ silver triflate loadings comprise depressed semicircles in the high-frequency region. Such semicircles are generally attributed to the bulk resistance of the polymer electrolyte [43]. The diameter of the semicircle is found to decrease with an increase in silver triflate loading, indicating an activated conduction mechanism in the nanocomposite films [43]. Due to the increased conductivity of the system with increasing silver loading, the complex impedance results indicate that the developed films have the potential to be

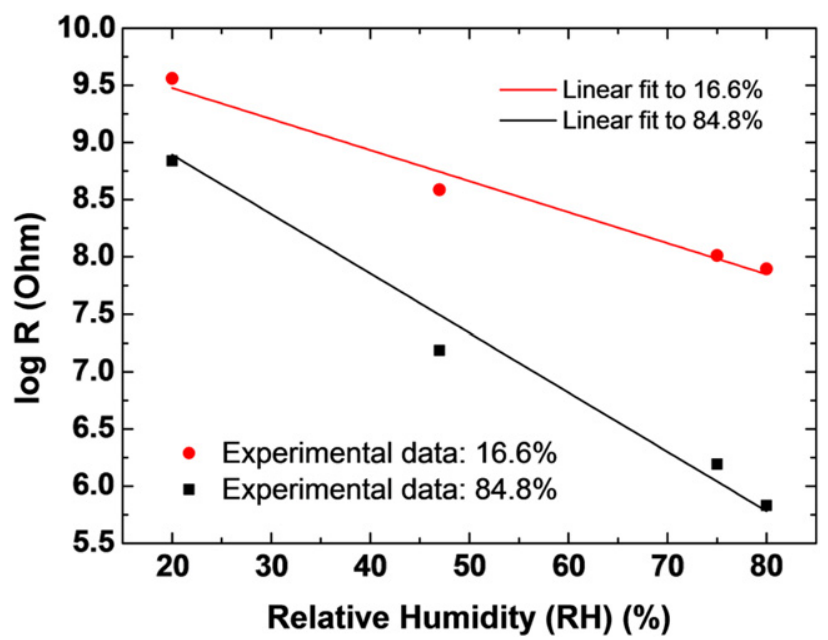

Figure 7. Logarithm of electrical resistance $R(\mathrm{Ohm})$ experimental data and relative fitting versus relative humidity in the $\mathrm{PEO} / \mathrm{AgCF}_{3} \mathrm{SO}_{3}$ nanocomposite films with $16.6 \%$ and $84.8 \%$ of silver salt.

utilized as polymer electrolytes. This will be the focus of a future work adding also lithium salts to the system.

Moreover, all the nanocomposite films present a linear Ohmic $I-V$ behavior as shown in figure 6(a), which exhibits the DC current-voltage $(I-V)$ data for the pure PEO films and $\mathrm{PEO} / \mathrm{Ag}$ compounds nanocomposite films, measured at room temperature. Figure 6(b) shows the DC electrical conductivity $\sigma\left(\mathrm{S} \mathrm{m}^{-1}\right)$ of the composite films as a function of silver triflate concentration in their initial solution. The conductivity was calculated taking into account the inverse slope of the data presented in figure 6(a) $(1 / R)$, the average thickness of the films $(t)$ measured by a profilometer $(\sim 15 \mu \mathrm{m})$, the length of the electrodes $(l)$ used, and the distance between them $(d)$, using the following equation:

$$
\sigma=d / R \times t \times l .
$$

For concentration levels up to $9.1 \mathrm{wt} \%$ of silver salt, the electrical conductivity shows very low values in the range $10^{-6}-10^{-4} \mathrm{~S} \mathrm{~m}^{-1}$, whereas at the maximum triflate loading (84.8 $\mathrm{wt} \%)$ it reaches $0.1 \mathrm{~S} \mathrm{~m}^{-1}$. All the conductivity measurements were performed at room temperature with a value of relative humidity of c.a. $80 \%$.

Two different kinds of composite film with different morphologies, obtained from solutions containing $16.6 \mathrm{wt} \%$ and $84.8 \mathrm{wt} \%$ of silver salt, exhibiting compact and nanofibrillar morphology, respectively, were chosen in order to study their sensitivity as humidity sensors. The DC electrical conductivity of these films at room conditions is highlighted by the two green star symbols in figure 6(b). DC current-voltage $(I-V)$ measurements were conducted under controlled relative humidity $(\mathrm{RH})$ environment conditions. In particular, the coatings were characterized under different humidity environments with relative humidity values of $20 \%, 47 \%, 75 \%$ and $80 \%$. Figure 7 shows the electrical resistance versus RH results obtained from such films. Using equation (2) we calculated the electrical conductivity $\sigma$ of the films. For the films obtained from the solution with $16.6 \mathrm{wt} \%$ 
of silver salt the conductivity varies in the range of the used $\mathrm{RH}$ between $10^{-5}$ and $1.5 \times 10^{-3} \mathrm{~S} \mathrm{~m}^{-1}$, whereas for those formed from the solution with $84.8 \mathrm{wt} \%$ of silver salt the conductivity varies between $3.98 \times 10^{-5}$ and $0.1 \mathrm{~S} \mathrm{~m}^{-1}$. The films obtained from $84.8 \mathrm{wt} \%$ silver salt loading were found to have higher sensitivity to relative humidity compared to the films obtained from the solution with $16.6 \mathrm{wt} \%$ silver salt. The sensitivity was determined from the slopes of the linear line fitting to the data shown in figure 7 (0.027 in the case of $16.6 \mathrm{wt} \%$ and 0.052 in the case of $84.8 \mathrm{wt} \%$ of silver salt). Higher sensitivity of the films prepared using the solution with $84.8 \%$ silver salt loading can be mainly attributed to the increased surface area of the self-assembled nanofibers with respect to flat films. On the top, it is very likely that the nanofibrous films have higher amounts of unreacted silver salt than the flat films. When humidity increases these amounts of salt can be dissolved, affecting the overall electronic conductivity of these systems.

In previous research works, when electrospun PEO fibers incorporating a different salt $\left(\mathrm{LiClO}_{4}\right)$ were employed as humidity sensors, the slopes were reported to be 0.063 [40] and 0.058 in [41], which are quite close to the one found here for the films composed of self-assembled nanofibers. When normal films were cast instead of electrospinning, the slopes were evaluated to be approximately 0.011 [40, 41]. Finally, other polymer-ceramic nanocomposites developed for humidity sensing applications, such as nanocomposites based on nanocrystals of ceramic dispersed in a quaternary acrylic resin (RMX) [44], reported a lower sensitivity of around 0.022 .

\section{Conclusions}

In conclusion, the morphology of silver nanoparticle/PEO nanocomposites prepared by in situ reduction of silver triflate during a simple solution casting procedure was investigated. The results of this study revealed the strong dependence of the morphology of the polymer matrix on silver triflate concentration, leading to nanofibrous PEO networks when high loads of silver salt are incorporated. To the best of our knowledge, this is the first example of a nanofibrous PEO nanocomposite morphology obtained by a simple drop casting technique. The films showed conductive behavior in ambient conditions, which renders them attractive as humidity sensors and for electronic devices in general. Overall, the process is highly reproducible, facile and inexpensive, since self-assembly occurs under ambient conditions.

\section{Acknowledgments}

The cross section preparation was performed by Helmut Gnaegi (Diatome Ltd). We gratefully acknowledge the technical support of the following people in characterization measurements: Dr M Manca, Dr F Spano, Dr S Karmakar, Dr G Bertoni, Mr R Giannuzzi and Ms A G Monteduro.

\section{References}

[1] Croce F, Appetecchi G B, Persi L and Scrosati B 1998 Nature 394456

[2] Quartarone E, Mustarelli P and Magistris A 1998 Solid State Ion. 110

[3] Gadjourova Z, Andreev Y G, Tunstall D P and Bruce P G 2001 Nature 412520

[4] Scrosati B and Vincent C A 2000 MRS Bull. 2528

[5] Kang Y, Cheong K, Noh K-A, Lee C and Seung D-Y 2003 J. Power Sources 119-121 432

[6] Stephan A M 2006 Eur. Polym. J. 4221

[7] Stephan A M and Nahm K S 2006 Polymer 475952

[8] Sunderrajan S, Freeman B D, Hall C K and Pinnau I 2001 J. Membrane Sci. 1821

[9] Kim J H, Park S M, Won J and Kang Y S 2005 J. Membr. Sci. 248171

[10] Liu L, Feng X and Chakma A 2004 Separ. Purif. Technol. 38255

[11] Chandra S, Hashmi S A, Saleem M and Agrawal R C 1993 Solid State Ion. 671

[12] Sreepathi Rao S, Satyanarayana Rao K V, Shareefuddin M, Subba Rao U V and Chandra S 1994 Solid State Ion. 67331

[13] Devendrappa H, Rao U V S and Prasad M V N A 2006 J. Power Sources 155368

[14] Spano F, Massaro A, Blasi L, Malerba M, Cingolani R and Athanassiou A 2012 Langmuir 283911

[15] Massaro A, Spano F, Cingolani R and Athanassiou A 2011 IEEE Sensors J. 111780

[16] Bayer I S et al 2011 ACS Appl. Mater. Interfaces 34024

[17] Chen Q, Zhou M, Fu Y, Weng J, Zhang Y, Yue L, Xie F and Huo C 2008 Surf. Coat. Technol. 2025576

[18] Yue L, Zhou M, Chen Q, Weng J and Zhang Y 2009 Vacuum 831200

[19] Favia P, Vulpio M, Marino R, d'Agostino R, Mota R P and Catalano M 2000 Plasmas Polym. 51

[20] Chen Q, Zhang Y, Yang L, Chen S, Weng J and Yue L 2009 J. Phys. Chem. C 1137633

[21] Chen Q, Yue L, Xie F, Zhou M, Fu Y, Zhang Y and Weng J 2008 J. Phys. Chem. C 11210004

[22] Kim J, Lee J, Kwon S and Jeong S 2009 J. Nanosci. Nanotechnol. 91098

[23] Sundaray B, Choi A and Park Y W 2010 Synth. Met. 160984

[24] Neubert S, Pliszka D, Thavasi V, Wintermantel E and Ramakrishna S 2011 Mater. Sci. Eng. B 176640

[25] An J, Zhang H, Zhang J, Zhao Y and Yuan X 2009 Colloid Polym. Sci. 2871425

[26] Suthanthiraraj S and Vadivel M 2012 Ionics 18385

[27] Suthanthiraraj S and Vadivel M 2012 Appl. Nanosci. 2239

[28] Gondaliya N, Kanchan D, Sharma P and Joge P 2011 Mater. Sci. Appl. 21639

[29] Strawhecker K E and Manias E 2003 Chem. Mater. 15844

[30] Bodor G 1991 Structural Investigation of Polymers (Ellis Horwood Series in Polymer Science and Technology) (New York: Ellis Horwood)

[31] Aziz S B, Abidin Z H Z and Arof A K 2010 Physica B 4054429

[32] Rogach A L, Shevchenko G P, Afanas'ev Z M and Sviridov V V 1997 J. Phys. Chem. B 1018129

[33] Shi Q, Vitchuli N, Nowak J, Noar J, Caldwell J M, Breidt F, Bourham M, McCord M and Zhang X 2011 J. Mater. Chem. 2110330

[34] Voronov A, Kohut A, Vasylyev S and Peukert W 2008 Langmuir 2412587

[35] Huang Z-M, Zhang Y Z, Kotaki M and Ramakrishna S 2003 Compos. Sci. Technol. 632223 
[36] Swanson H E, Morris M C, Evans E H, Paretzkin B, Parker H S and Panagiotopoulos N C 1981 Standard X-ray Diffraction Powder Patterns (USA: National Bureau of Standards)

[37] Gao X-Y, Wang S-Y, Li J, Zheng Y-X, Zhang R-J, Zhou P, Yang Y-M and Chen L-Y 2004 Thin Solid Films 455/456 438

[38] PiersonT J F and Rousselot C 2005 Surf. Coat. Technol. 200276
[39] Deitzel J M, Kleinmeyer J D, Hirvonen J K and Beck Tan N C 2001 Polymer 428163

[40] Aussawasathien D, Dong J H and Dai L 2005 Synth. Met. 15437

[41] Lin Q, Li Y and Yang M 2012 Sensors Actuators B 161967

[42] Pielichowski K and Flejtuch K 2005 J. Anal. Appl. Pyrolysis 73131

[43] Bhide A and Hariharan K 2007 Eur. Polym. J. 434253

[44] Wang J, Lin Q, Zhou R and Xu B 2002 Sensors Actuators B 81248 